\title{
Programa institucional de bolsas de iniciação à docência do curso de história da Universidade Federal do Pampa
}

\author{
Programa institucional de bolsas de iniciación a la docencia del \\ curso de historia de la Universidad Federal del Pampa \\ Institutional program of initiation bags to the teaching of the history \\ course of the Federal University of Pampa
}

\author{
Maria Eduarda Franco Gallo ${ }^{1}$ \\ Jônatas Marques Caratti²
}

\begin{abstract}
Resumo
O presente trabalho tem como finalidade mostrar alguns aspectos preliminares do projeto de pesquisa em desenvolvimento no Campus de Jaguarão da Universidade Federal do Pampa (UNIPAMPA). O objetivo geral dessa pesquisa é mostrar um pouco do que se foi trabalho nesses últimos seis meses de projeto. Dentro dessetemos os objetivos específicos do nosso sub-projeto multidisciplinar e um deles seria a superação, por meio da investigação do conhecimento histórico, de problemas presentes na sociedade jaguarense como, ódio de classe, raça e gênero, clientelismo, coronelismo, racismo cotidiano e institucionalizado.A ideia inicial do projeto era conhecer e se inserir dentro do âmbito escolar e também dentro da comunidade em que a escola a ser trabalhada esta inserida. Para que isso pudesse ocorrer os bolsista foram até a escola para conhecer o local que futuramente seria trabalhado, conheceram também o centro comunitário, fizeram uma roda de conversa com os pais dos alunos, participaram de atividades do bairro, como as festas infantis realizadas pelo centro comunitário Esse diálogo aberto com a comunidade foi a metodologia usada durante esse início do projeto.Outra atividade que foi desenvolvida foi a integração de futuros professores com os futuros alunos através de oficinas extracurriculares que iam do campo artístico até a brincadeiras de rua. No fim desses seis meses de trabalho o projeto de instalou dentro da escola e do bairro, conseguiu se aproximar do alunos e desenvolver leituras pedagógicas e de história local.
\end{abstract}

Palavras-chaves: Formação de professores, sala de aula, projeto de pesquisa, educação, história local

\section{Resumen}

El vigente trabajo tiene como finalidad mostrar algunos aspectos, en cierto modo parciales, del proyecto de investigación en desarrollo en el Campus de Jaguarão de la Universidad Federal de Pampa. El objetivo general de esta investigación es mostrar un poco de lo que se ha trabajado en estos últimos seis meses de proyecto. En el marco de este objetivo, los objetivos específicos de nuestro sub-proyecto multidisciplinario y uno de ellos sería la superación, a través de la investigación del conocimiento histórico, de problemas presentes en la sociedad jaguarense como, odio de clase, raza y género, clientelismo, coronelismo, racismo cotidiano y racismo institucionalizada. La idea inicial del proyecto era conocer e insertarse dentro del ámbito escolar y también dentro de la comunidad en que la escuela a ser trabajada esta insertada. Para que esto pudiera ocurrir, los becarios fueron a la escuela para conocer el local que en el futuro sería trabajado, conocieron también el centro comunitario, hicieron una rueda de conversación con los padres de los alumnos, participaron de actividades del barrio, como las fiestas infantiles realizadas por el centro Este diálogo abierto con la comunidad fue la

${ }^{1}$ Graduanda do Curso de Licenciatura em História da Universidade Federal do Pampa, UNIPAMPA; Jaguarão/RS, Brasil.

${ }^{2}$ Doutor em História pela UFRGS. Professor Adjunto do Curso de Licenciatura em História da Universidade Federal do Pampa, UNIPAMPA; Jaguarão/RS, Brasil. 
metodología utilizada durante ese inicio del proyecto. Otra actividad que fue desarrollada fue la integración de futuros profesores con los futuros alumnos a través de talleres extracurriculares que iban desde el campo artístico hasta los juegos de calle. Al final de esos seis meses de trabajo el proyecto de instaló dentro de la escuela y del barrio, logró acercarse a los alumnos y desarrollar lecturas pedagógicas y de historia local.

Palabras claves: Formación de profesores, sala de aula, proyecto de investigación, educación, historia local.

\begin{abstract}
The current work aims to show some aspects, somehow partial, of the research project under development at the Jaguarão Campus of the Federal University of Pampa. The overall objective of this research is to show a little of what has been work in the last six months of the project. Within this, we have the specific objectives of our multidisciplinary subproject and one of them would be the overcoming, through the investigation of historical knowledge, of problems present in Jaguar society such as class hatred, race and gender, clientelism, coronelism, everyday racism and institutionalized. The initial idea of the project was to know and to insert within the school scope and also within the community in which the school to be worked is inserted. In order for this to happen the students went to the school to meet the place that would be worked in the future, they also visited the community center, made a round of conversation with the parents of the students, participated in activities in the neighborhood, such as children's parties held by the center This open dialogue with the community was the methodology used during this project start. Another activity that was developed was the integration of future teachers with the future students through extracurricular workshops that went from the artistic field to the street plays. At the end of these six months of work, the project installed inside the school and the neighborhood, managed to approach the students and develop pedagogical readings and local history.
\end{abstract}

Keywords: Teacher training, classroom, research project, education, local history.

\title{
1.Uma breve contextualização sobre o projeto
}

Os primeiros encontros do Núcleo História do PIBID UNIPAMPA tiveram início em agosto de 2018. Logo nas primeiras reuniões, percebeu-se a necessidade de conhecer a realidade da escola e do próprio bairro onde a mesma estava inserida. Era importante que os bolsistas de ID (Iniciação à Docência) percebessem o cotidiano escolar, as dificuldades dos professores com a prática, para que pudessem, a partir disso, pensar metodologias inovadoras para a sala de aula. Para que isso fosse perceptível aos bolsistas, os mesmos observaram aulas da disciplina de História dos anos finais do fundamental, da Escola Municipal Dr. Fernando Ribas, situado na periferia de Jaguarão/RS.

Os professores e professoras em formação detectaram na análise do cotidiano escolar o seguinte: baixo desempenho nas aulas, falta de estímulo, metodologias tradicionais de ensinoaprendizagem e dificuldades nas relações inter-pessoais entre estudantes e professores. Para superar estes desafios, é importante que o docente tenha uma postura e se identifique com o que Donald Schön (1983) chama de "professor reflexivo", ou ainda Lawrence Stenhouse (1975), intitula de "professor-pesquisador". Estes conceitos têm sido apresentados e 
discutidos por diversos autores contemporâneos e, para uma compreensão sintética do debate, sugerimos a leitura do texto de Tatiana Bezerra Fagundes (2016). ${ }^{3}$

O projeto de pesquisa PIBID- Programa Institucional de Bolsa de Iniciação à Docência, surge como uma potencial alternativa para o fortalecimento da formação inicial. Ele consegue conectar os saberes encontrados dentro da universidade com os saberes que se constroem cotidianamente nas escolas. A vivência de professor que exerce na educação básica é extremamente enriquecedora para um aluno que está em sua formação inicial dentro da universidade, tornando-os assim futuros profissionais mais capacitados, pois conhecem a vivência dentro de sala de aula desde os primeiros anos de graduação. O objetivo geral desse texto é trazer para o leitor, de forma parcial, aspectos que foram trabalhos no projeto durante os meses de agosto até novembro de 2018 (dois mil e dezoito), com a exposição das ações realizadas, relatos falados dos bolsistas e imagens.

\section{Descrição das ações iniciais realizadas pelo projeto}

Após a primeira reunião com coordenador de área, Prof. Jônatas Marques Caratti e a supervisora Prof ${ }^{a}$ Berenice Aquino (que ocorreu dia 16 de agosto de 2018), foi decidido que inicialmente o foco do projeto se daria na introdução dos bolsista no âmbito acadêmico e social do Bairro Vencato, localizado na periferia de Jaguarão/RS. De modo complementar à análise da realidade, realizou-se leituras de textos acadêmicos que permitissem uma melhor compreensão da escola, do bairro e da cidade. A primeira ação prática foi uma visita a Escola Municipal Dr. Fernando Corrêa Ribas que se situa no Bairro Vencato da cidade de Jaguarão$\mathrm{RS}$, onde os bolsistas e o coordenador do projeto tiveram a oportunidade de conhecer o futuro local de trabalhos, o corpo docente, a equipe diretiva e os estudantes matriculados na instituição. Nessa visita, os bolsistas tiveram uma breve conversa com os professores e na sequiência passaram de sala em sala, conhecendo e se apresentando aos alunos de $6^{\circ}$ (sexto) ao $9^{\circ}$ (nono) ano do Ensino Fundamental II.

\footnotetext{
${ }^{3}$ FAGUNDES, Tatiana Bezerra. Os conceitos de professor pesquidador e professor reflexivo. Os conceitos de professor pesquisador e professor reflexivo: perspectivas do trabalho docente. In: Revista Brasileira de Educação, Volume 21, número 65, 2016.
} 


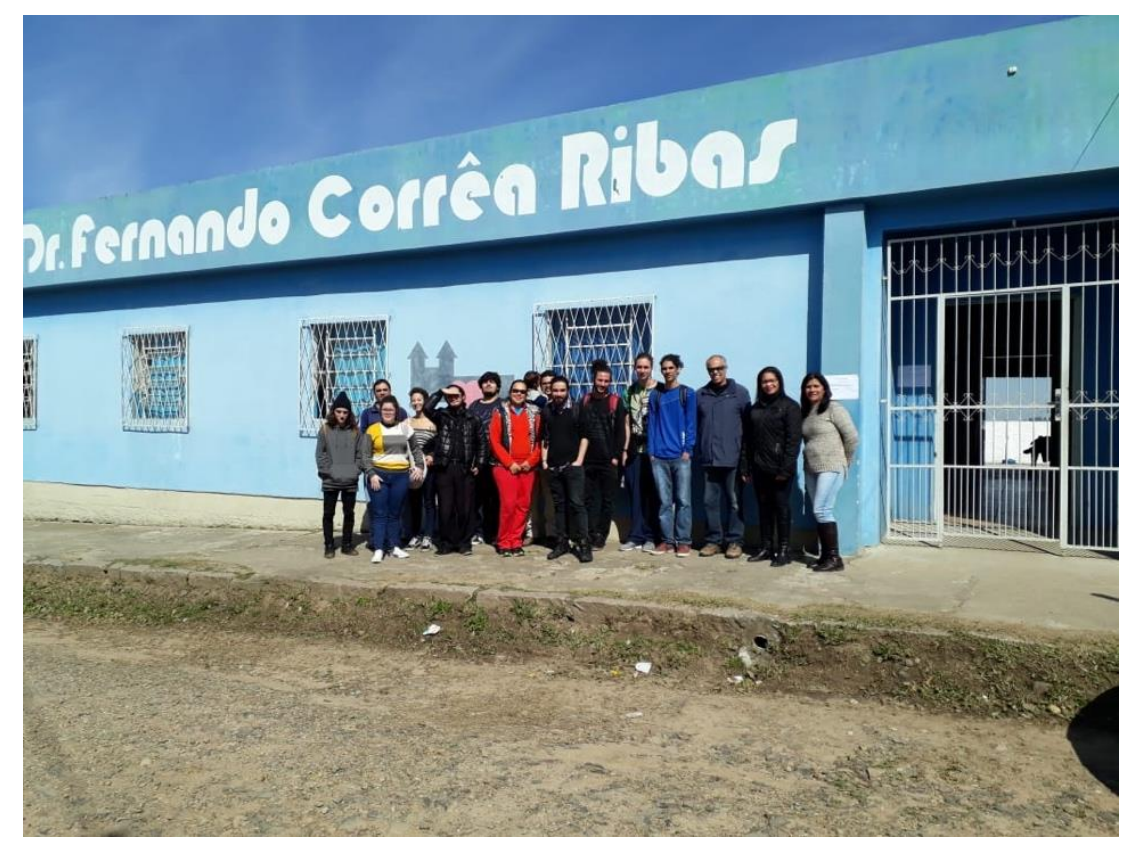

Figura: Visitação inicial do projeto a Escola Municipal Dr. Fernando Corrêa Ribas

Após a visita à escola, percebeu-se a necessidade de compor forças para que o Núcleo História do PIBID tivesse êxito. Na prática isso significava dialogar com todas as partes responsáveis pela educação dos estudantes. Por isso, solicitamos à equipe diretiva que fosse marcada uma reunião com o CPM (Conselho de Pais e Mestres) da escola. Isso nos permitia conhecer os pais e saber suas expectativas, bem como a forma que poderíamos nos inserir na escola e ter uma relação aprazível com seus filhos. Os pais que participaram da reunião (cerca de dez) foram muitos solícitos e trouxeram informações de grande valia para o projeto.

Naquele momento, percebemos que os problemas da comunidade eram muitas vezes trazidos para à escola, contudo, a instituição escolar, por ser tradicional e engessada em seus objetivos de conteúdo formal, não dava conta de contribuir para sanar estes problemas. Como solicitação por parte dos pais, registramos suas principais demandas: educação ambiental (cuidado com o bairro), melhorar a auto-estima dos estudantes, desenvolver o gosto pelo estudo, além de fortalecer o compromisso e a responsabilidade dos mesmos. 


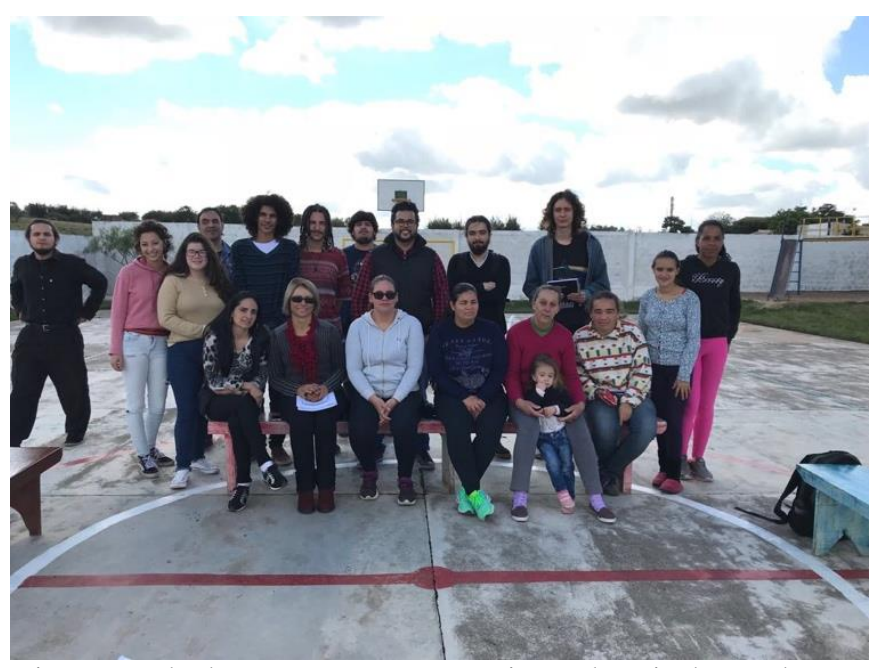

Figura: Roda de conversa com a comissão de pais da escola.

Com um trabalho sendo desenvolvido dentro da escola, era o momento de ser trabalhar com o bairro, pois dentro do projeto temos o objetivo de valorização e conscientização da história local, para que se tenha um sentimento de pertencimento dentro de sua própria cidade/bairro. A primeira ação foi a leitura do trabalho de conclusão de curso da Fladiane Teixeira que é intitulado, “O Vencato a partir da memória de seus moradores: do loteamento a construção do bairro". O texto trata-se exclusivamente da história do bairro Vencato, que é onde se situa a Escola Dr. Fernando Corrêa Ribas, aborda desde o momento em que terras começaram a ser vendidas e doadas, até a última construção de infraestrutura que chegou ao bairro, no caso o posto de saúde.

Ainda com o objetivo de compor forças, o coordenador de área, a supervisora da escola e os dez bolsistas de ID foram conhecer o Centro Comunitário da Vila Vencato, fundado em 1986 e que foi instituição fundamental para conquistar coisas básicas para o bairro. Na conversa com o atual presidente, conhecido como "Zé da Vencato", notamos que atualmente a comunidade está muito desarticulada e que a própria memória do bairro está se perdendo. Assim, uma forma encontrada para que o Centro Comunitário fosse ocupado pelos moradores, foi oferecermos diversas oficinas pedagógicas, que visavam tanto se aproximar com os estudantes da escola, como fazer uso de suas dependências. 


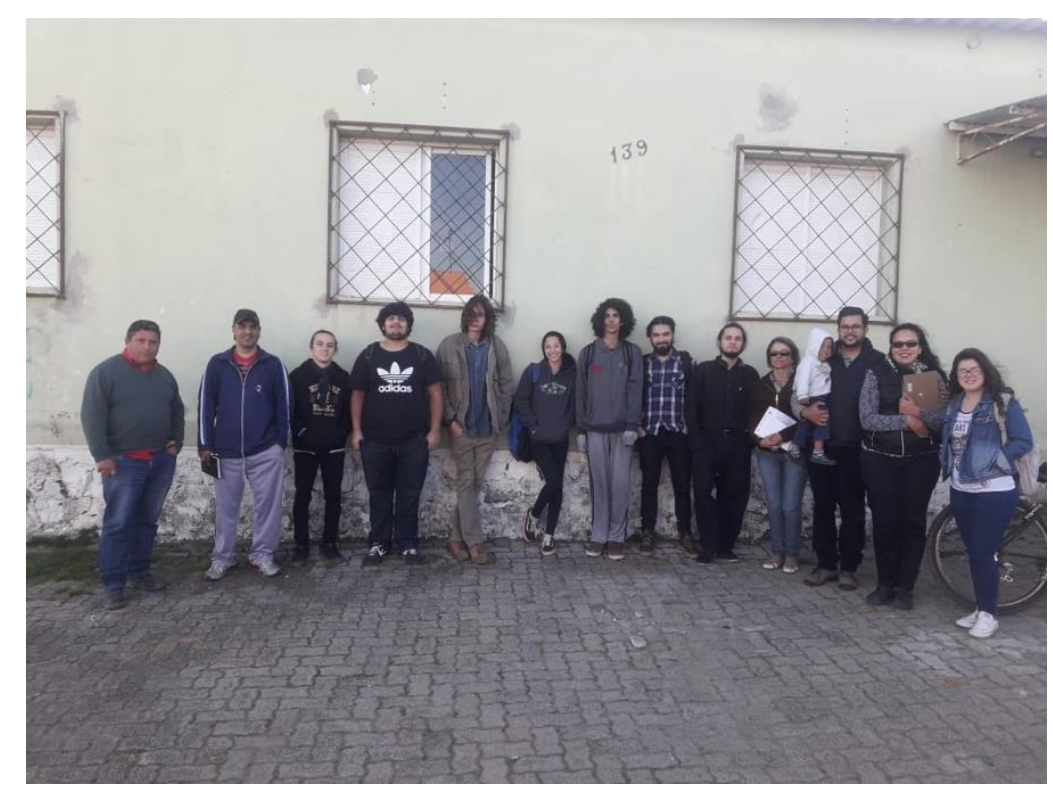

Figura: Roda de conversa com o presidente do Centro Comunitário do Bairro Vencato

Outro contato fundamental para fortalecer o Núcleo PIBID História, foi conhecer a equipe pedagógica da SMED (Secretária Municipal de Educação e Desporto), buscando dados que nos permitissem entender a realidade escolar do município, bem como da própria escola adotada. Temas como evasão escolar, por exemplo, foram discutidos e o PIBID História colocou-se à disposição para ajudar a secretaria a escol, propiciando espaço de construção de conhecimento e metodologias inovadoras.

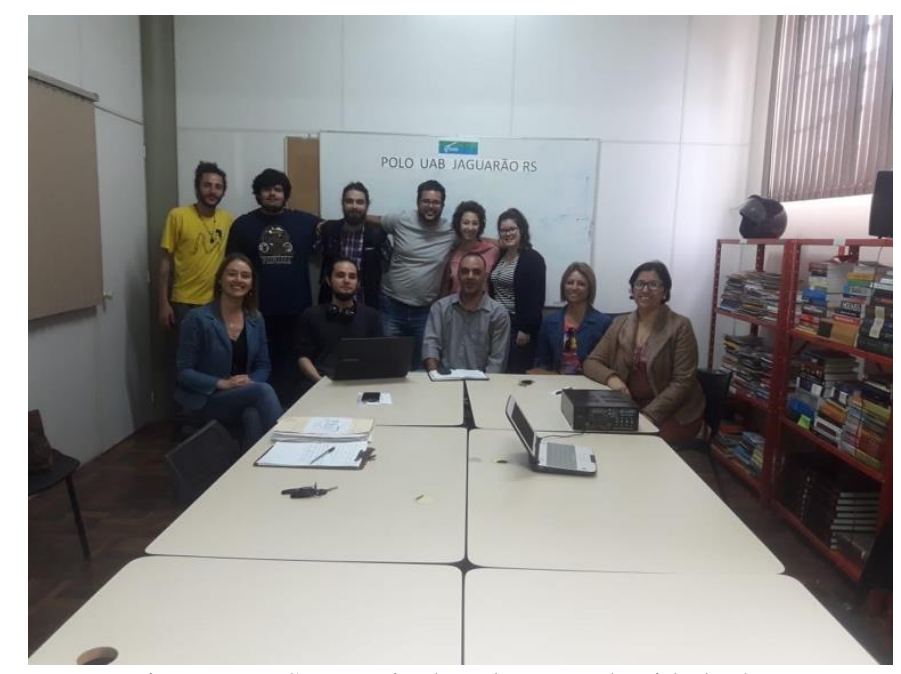

Figura: Reunião com a Secretaria de Educação da cidade de Jaguarão- SMED

\section{As primeiras experiências práticas: oficinas extracurriculares}

Logo nas primeiras reuniões já havia a intenção de que ainda no ano de 2018 (dois mil e dezoito) os bolsistas tivessem um contato pratico com os alunos, para que assim uma pré- 
relação fosse estabelecida entre os estudantes e futuros professores. Com esse pensamento em mente, dentro de algumas reuniões descobrimos que cada bolsista já havia atuado em um campo extracurricular diferente, como dança, circo, teatro, xadrez e outros. Surgiu aí a idéia de que cada um dos bolsistas ministrasse oficinas gratuitas para o discente da Escola Municipal Dr. Fernando Corrêa Ribas.

Ainda com objetivo de se fazer surgir um sentimento de pertencimento dentro da comunidade, foi decidido que as oficinas ocorreriam no Centro Comunitário do bairro, para que essa nova geração tivesse este espaço como um lugar inerente da sua história, tanto nas lutas e conquistas que ele alcançou no passado, mas também como uma história vivenciada no presente dos mesmos. Após alguns encontros e diálogos dentro do projeto, foi decidido que seriam ministradas sete oficinas, sendo elas: circo, teatro, flauta, violão, dançar urbanas, brincadeiras de rua e xadrez. Elas iriam ocorrem durante a semana no contra-turno.

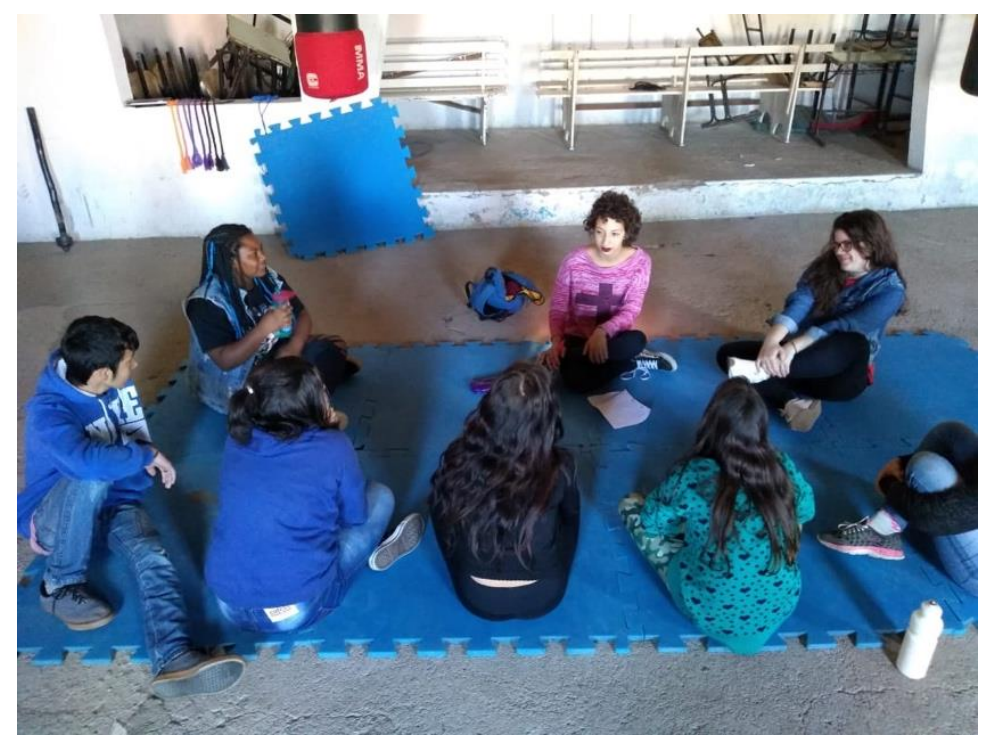

Figura I: Oficina de Teatro 


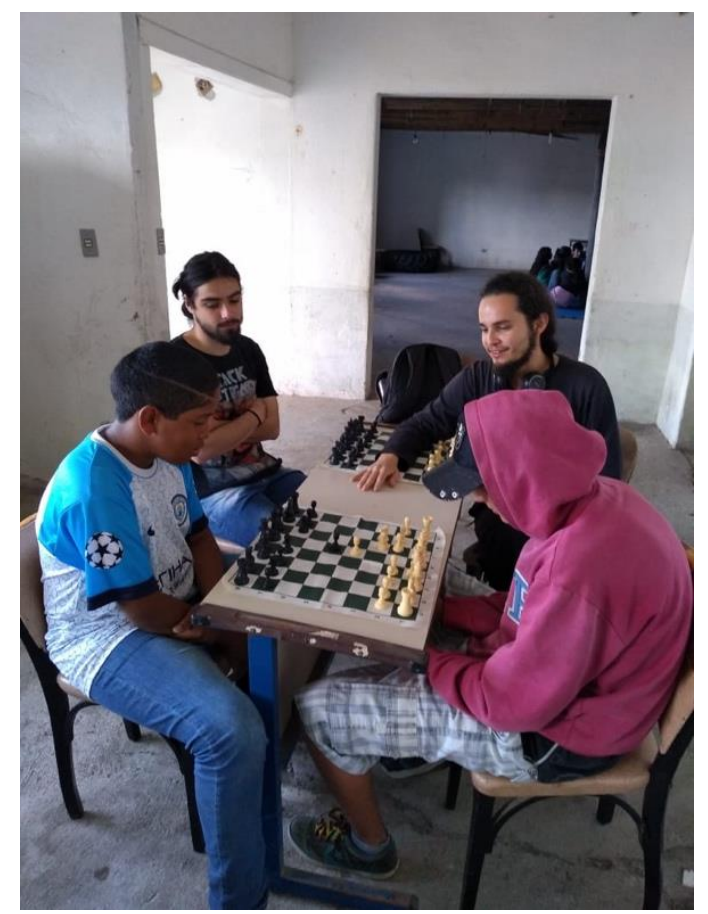

Figura II: Oficina de xadrez

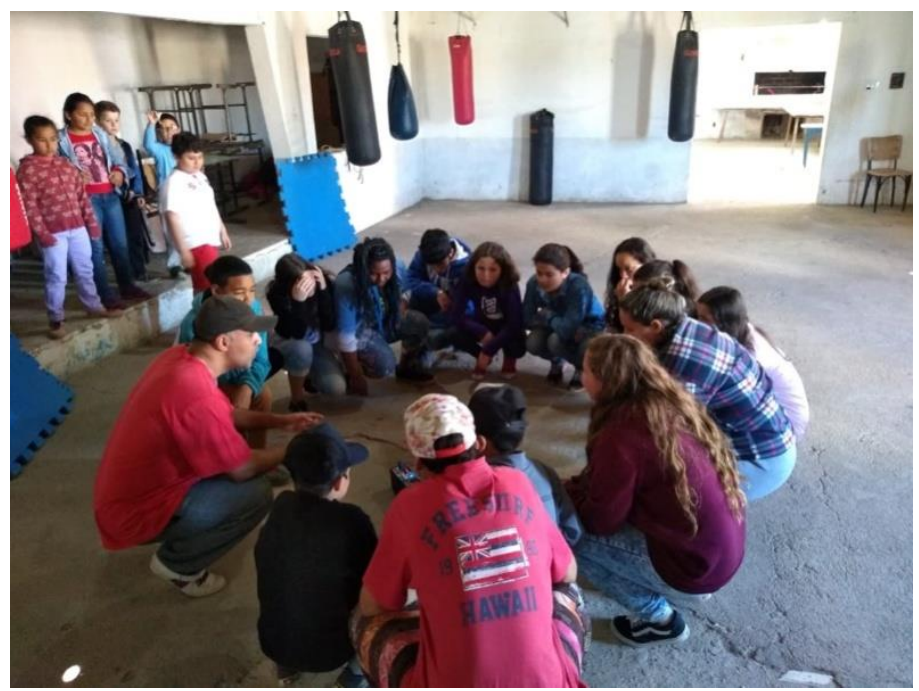

Figura III: Oficina de danças urbanas

As oficinas tiveram a duração de dois meses, tendo início na primeira semana de outubro e sendo finalizada no início de dezembro. Pelos relatos dos bolsistas, a oportunidade de ministrar oficinas foi uma ótima maneira de iniciar as ações mais práticas do projeto. Podemos observar pelo relato de um dos bolsistas:

"Me chamo Guilherme Mallet, sou discente do quinto semestre do curso de Licenciatura em História da Universidade Federal do Pampa - Campus Jaguarão. Neste segundo semestre de 2018, ministrei a oficina de violão, que ocorria nas quartas feiras no Centro Comunitário do Bairro Vencato. No período em que a oficina foi oferecida, tivemos um bom proveito, nem todos os alunos tiveram uma 
boa freqüência, porém os frequentes obtiveram um ótimo resultado. Foi uma experiência muito importante não somente para os alunos mas também para nós instrutores, que logo no início do projeto já tivemos um contato bem próximo com os alunos que trabalharemos neste ano de 2019."

\section{Considerações finais}

Nesse curto espaço de tempo em que trabalhamos com a Escola Municipal de Ensino Fundamental Dr. Fernando Corrêa Ribas, foi um período que troca de experiência intensa. Em que os bolsistas tiveram a oportunidade de conhecer a realidade prática daquilo que é visto dentro do ambiente acadêmico, perceber as dificuldades, conhecer sobre a história local, entre outros aspectos de grande valor. Com a atividade prática de ensino, eles acabaram desenvolvendo novas formas pedagógicas de ensino que servirá durante o ano de 2019 (dois mil e dezenove) quando entraram efetivamente na sala de aula, também haverá um conhecimento prévio de seu alunos. Apesar das dificuldades que acabaram surgindo durante esse tempo, se pode perceber um grande interesse dos discentes e dos docentes pelo projeto, uma vontade de aprender e de ensinar que seja diferente da concepção bancária que Paulo Freire tanto critica. Onde aluno-professor aprendam e ensinem juntos, uma educação que o faça se sentir desafiado.

\section{Referências}

BECKER, Fernando. Modelos pedagógicos e modelos epistemológicos. Educação e Realidade, Porto Alegre; 1994. Pág. 13-30.

FREIRE, Paulo. Pedagogia do oprimido. Paz e Terra, Rio de Janeiro; 1987. Pág. 7-21; 65-87. SCHÖN, Donald. Educando o profissional reflexivo: um novo design para o ensino e a aprendizagem. Artes Médicas: Porto Alegre, 2000.

STENHOUSE, Lanrence. And introduction do curriculum research and development, Londres \& New York, 1975.

TEIXEIRA, Fladiane. O Vencato a partir da memória de seus moradores: do loteamento a construção do bairro. Universidade Federal do Pampa; 2015. 